\title{
LUMPY SKIN DISEASE: AN INSIGHT TO EPILEPSY
}

\author{
Sushruth G. Kamoji ${ }^{1}$, Pooja Devi Malipatil2 ${ }^{2}$ Malteshgouda N. Patil ${ }^{3}$
}

\section{HOW TO CITE THIS ARTICLE:}

Sushruth G. Kamoji, Pooja Devi Malipatil, Malteshgouda N. Patil.“Lumpy Skin Disease: An Insight to Epilepsy”. Journal of Evolution of Medical and Dental Sciences 2015; Vol. 4, Issue 10, February 02; Page: 1723-1726,

DOI: $10.14260 /$ jemds/2015/246

ABSTRACT: Cycticercosis is a parasitic infection resulting from ingestion of eggs of Taenia solium, the pork tapeworm. Cutaneous cysticercosis can be a clinically indolent disease or can be associated with subcutaneous nodules, visceral and CNS involvement. Their presence signals the search for systemic involvement, especially neurocysticercosis. Cutaneous cysticercosis has been rarely reported in literature.

KEYWORDS: Cysticercosis, epilepsy, subcutaneous nodules.

INTRODUCTION: Cysticercosis is a parasitic infection caused by Cysticercus cellulosae, a larval stage of the pork tapeworm, Taenia solium. The commonest form is neurocysticercosis seen in $60-90 \%$ of patients.[1] It is also one of the main causes of seizures and epilepsy, especially in the developing world.[2] The disease is most prevalent in countries where pigs are reared and consumed raw or undercooked due to the lack of meat inspection.[3] Cysticerci can develop in any organ in humans, but are more commonly found in the brain, skeletal muscles and subcutaneous tissue. An uncommon case of extensive cutaneous cysticercosis guiding the diagnosis of neurocysticercosis is reported here, as the association of subcutaneous nodules with neural cysticercosis is rare.[1]

CASE REPORT: 22 year old male presented with multiple firm nodules on the skin of 2years duration, distributed over the neck, arms, abdomen, back and thighs (Figures 1- 4). The lesions measured about 1 to $1.5 \mathrm{~cm}$, round to elliptical in shape and were asymptomatic. The lesions were slowly progressive in size, but the numbers increased rapidly. Patient gave history of consumption of pork on several occasions. He also complained of multiple episodes of seizures in the past few months. An intact vesicle was obtained at the time of biopsy (Figure 5) and the HPE revealed invaginated scolex (Figure 6). CT scan of the head \& neck showed multiple nodules scattered diffusely in the cerebrum and cerebellum in various stages of evolution (Colloid, vesicular \& calcified cysts) (Figure 7-8). Multiple scolices in vesicular stage were noted in the temporalis and occipital muscles. Ophthalmic examination ruled out eye involvement. We started the patient on oral albendazole $(15 \mathrm{mg} / \mathrm{kg} / \text { day })^{[4]}$ and phenytoin $(5 \mathrm{mg} / \mathrm{kg} /$ day $)$.

DISCUSSION: Taenia solium is a two-host zoonotic cestode. Human beings are the only definitive host and harbour the adult tapeworm, whereas both humans and pigs can act as intermediate hosts and harbour the larvae or cysticerci. Human infection with cysticercosis is due to ingestion of eggs in contaminated food or by reverse peristalsis of eggs or proglottides from the intestine to stomach. Oncospheres hatched from eggs enter the general circulation and form cysts in various parts of the body. In skin and subcutaneous tissue the lesions are usually painless, firm rubbery nodules containing cysticerci.[5] Tapeworm infestation is common in developing countries where crowding 


\section{CASE REPORT}

and poor sanitary conditions allow many opportunities for faecal contamination of food and water. Cysticercosis is the most common parasitic disease of the central nervous system worldwide.[6]

Singrodia et al, reported a similar case of subcutaneous cysticercosis preceding the diagnosis of neurocysticercosis in a 4 year old female child.[1] Arora et al, presented a study on cutaneous, mucocutaneous and neurocutaneous cysticercosis in which 33 patients of cutaneous cysticerci were examined, out of which 29 gave history of seizures. CT scan of brain revealed cysticercosis in 27 patients.[7] Cutaneous cysticerci do not carry any risk to the patient's health, but they are often a pointer to the involvement of internal organs.

In the present case, an absolute diagnosis of neurocutaneous cysticercosis was established by demonstrating the parasite within the nodule with the help of histopathological examination and neuroimaging studies.[8] Neurocysticercosis is not a common disease but the evaluation of subcutaneous nodules leading to its diagnosis is very rarely reported in the literature. This once again highlights the fact that skin can be a window to the internal milieu.

\section{REFERENCES:}

1. Singrodia S, Joshi RG, Solanki RB, Rawal RC. Subcutaneous nodules preceding convulsions due to neural cysticercosis. Indian Journal of Dermatology, Venereology and Leprology. 2008; 74 (4): 385-386.

2. Singhi P. Infectious causes of seizures and epilepsy in the developing world. Developmental Medicine \& Child Neurology. 2011, 53:600-609.

3. Ito A, Li T, Chen X, Long C, Yanagida T, Nakao M, et al. Mini review on chemotherapy of taeniasis and cysticercosis due to Taenia solium in Asia, and a case report with 20 tapeworms in China. Tropical Biomedicine. 2013; 30(2): 164-173.

4. Schmidt DK, Jordaan HF, Schneider J W, Cilliers J. Cerebral and subcutaneous cysticercosis treated with albendazole. Int J Dermatol. 1995; 34: 574-9.

5. Garcia HH, Gonzales AE, Evans CAW, Gilman RH. Taenia solium cysticercosis. Lancet. 2003; 362: 547-556.

6. DeGiorgio MC, Medina MT, Duron R, Zee C, Escueta SP. Neurocysticercosis. Epilepsy Curr. May 2004; 4 (3): 107-111.

7. Arora PN, Sanchetee PC, Ramakrishnan KR, Venkataram S. Cutaneous, mucocutaneous and neurocutaneous cysticercosis. Indian Journal of Dermatology, Venereology and Leprology. 1990; 56 (2): 115-118.

8. Del Brutto OH, Wadia NH, Dumas M, Cruz M, Tsang VC, Schantz PM. Proposal of diagnostic criteria for human cysticercosis and neurocysticercosis. J Neurol Sci. Oct 1996; 142 (1-2): 1-6. 


\section{CASE REPORT}

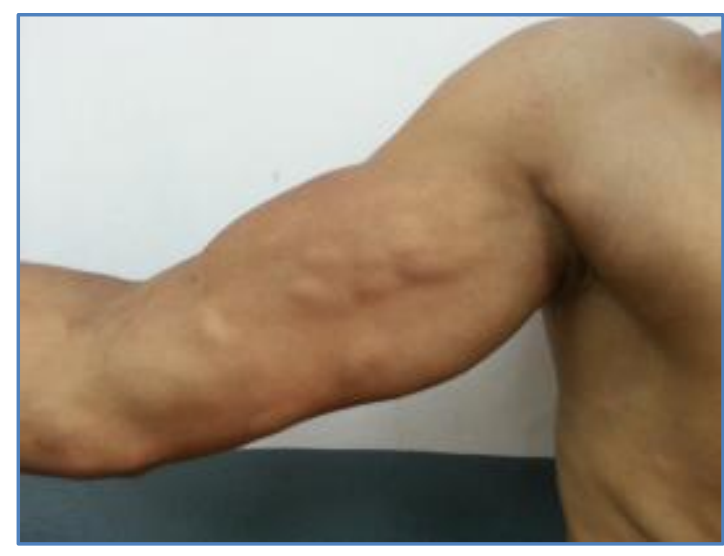

Fig. 1

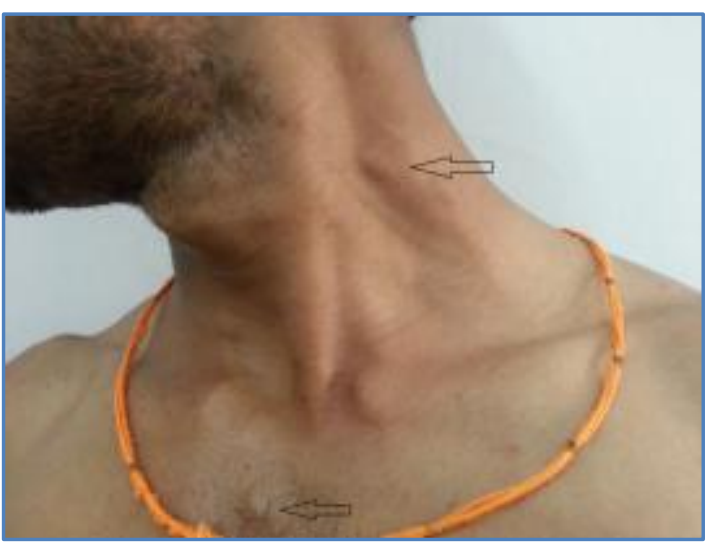

Fig. 3

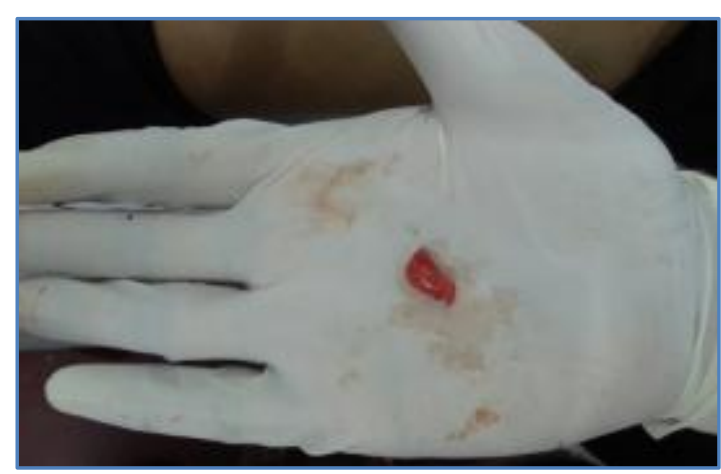

Fig. 5

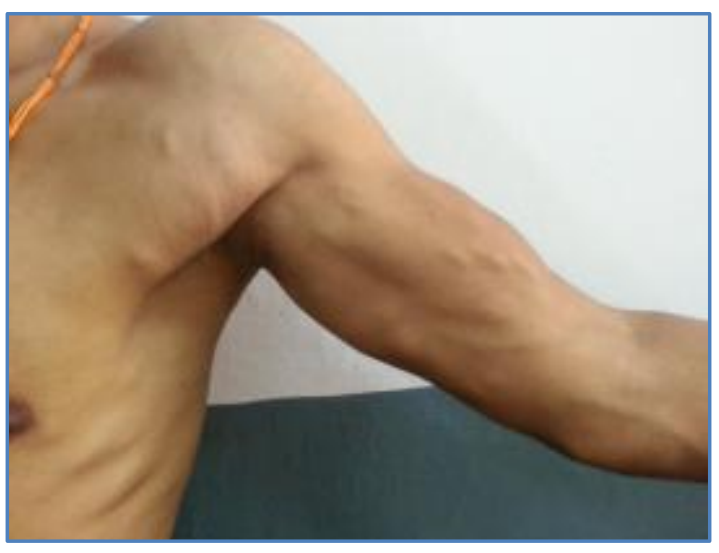

Fig. 2

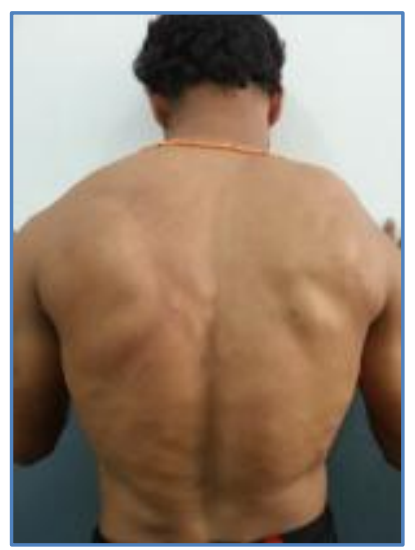

Fig. 4

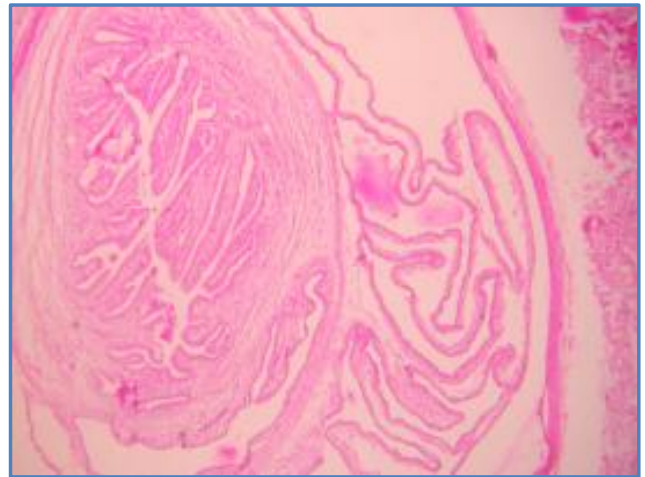

Fig. 6 


\section{CASE REPORT}

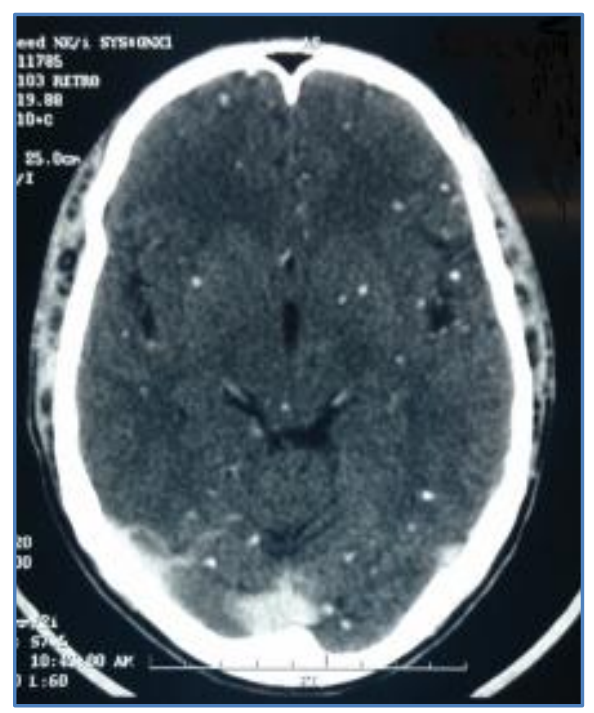

Fig. 7

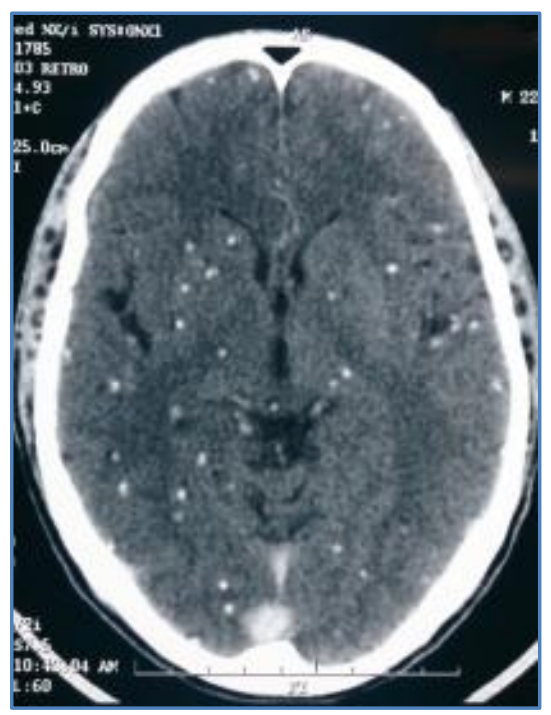

Fig. 8

\section{AUTHORS:}

1. Sushruth G. Kamoji

2. Pooja Devi Malipatil

3. Malteshgouda N. Patil

\section{PARTICULARS OF CONTRIBUTORS:}

1. Resident, Department of Dermatology, Belgaum Institute of Medical Sciences, Belgaum.

2. Post Graduate, Department of Dermatology, Belgaum Institute of Medical Sciences, Belgaum.

3. Professor and HOD, Department of Dermatology, Belgaum Institute of Medical Sciences, Belgaum.

\section{NAME ADDRESS EMAIL ID OF THE CORRESPONDING AUTHOR:}

Sushruth G. Kamoji,

Flat 204, Doctor's Quarters, Opposite HDFC Bank,

Civil Hospital Campus,

Belgaum, Karnataka.

E-mail: drsushruthk@yahoo.co.in

Date of Submission: $17 / 12 / 2014$.

Date of Peer Review: 18/12/2014.

Date of Acceptance: 22/01/2015.

Date of Publishing: 02/02/2015. 